\title{
TU/e EN⿴HONE

\section{Diagnostic analysis of radio propagation in UMTS networks using high-resolution angle-of-arrival measurements}

\section{Citation for published version (APA):}

Kwakkernaat, M. R. J. A. E., \& Herben, M. H. A. J. (2011). Diagnostic analysis of radio propagation in UMTS networks using high-resolution angle-of-arrival measurements. IEEE Antennas and Propagation Magazine, (1), 67-75.

Document status and date:

Published: 01/01/2011

\section{Document Version:}

Publisher's PDF, also known as Version of Record (includes final page, issue and volume numbers)

\section{Please check the document version of this publication:}

- A submitted manuscript is the version of the article upon submission and before peer-review. There can be important differences between the submitted version and the official published version of record. People interested in the research are advised to contact the author for the final version of the publication, or visit the $\mathrm{DOI}$ to the publisher's website.

- The final author version and the galley proof are versions of the publication after peer review.

- The final published version features the final layout of the paper including the volume, issue and page numbers.

Link to publication

\section{General rights}

Copyright and moral rights for the publications made accessible in the public portal are retained by the authors and/or other copyright owners and it is a condition of accessing publications that users recognise and abide by the legal requirements associated with these rights.

- Users may download and print one copy of any publication from the public portal for the purpose of private study or research.

- You may not further distribute the material or use it for any profit-making activity or commercial gain

- You may freely distribute the URL identifying the publication in the public portal.

If the publication is distributed under the terms of Article $25 \mathrm{fa}$ of the Dutch Copyright Act, indicated by the "Taverne" license above, please follow below link for the End User Agreement:

www.tue.nl/taverne

Take down policy

If you believe that this document breaches copyright please contact us at:

openaccess@tue.nl

providing details and we will investigate your claim. 


\title{
Diagnostic Analysis of Radio Propagation in UMTS Networks Using High-Resolution Angle-of-Arrival Measurements
}

\author{
Maurice R. J. A. E. Kwakkernaat ${ }^{1}$ and Matti H. A. J. Herben ${ }^{2}$ \\ ${ }^{1}$ TMC Electronics \\ 5600 AS, Eindhoven, The Netherlands \\ Tel: +31 40239 2260; Fax: +31 40239 2270; E-mail: maurice.kwakkernaat@tmc.nl
} (Formerly with Eindhoven University of Technology)

${ }^{2}$ Eindhoven University of Technology

$5600 \mathrm{MB}$, Eindhoven, The Netherlands

Tel: +31 40247 3594; Fax: +31 40245 5197; E-mail: m.h.a.j.herben@tue.nl

\begin{abstract}
This work describes high-resolution propagation measurements performed as a diagnostic survey in an operational UMTS network. The results were obtained using the measurement system previously presented in [1]. Measurements were performed in a dense urban environment in Amsterdam, the Netherlands. Results showed that the measurement approach can be used to create a setup that is similar to the actual network scenario, and that is capable of accurately identifying the dominant propagation effects while moving through the environment. The results are especially important for mobile-system operators, because they revealed some of the causes of inadequate propagation prediction. This underlined the limitations of propagation-prediction models currently used by most mobile-system operators, and the importance of accurate propagation information to obtain the optimal network configuration.
\end{abstract}

Keywords: Delay estimation; direction of arrival estimation; land mobile radio; land mobile radio cellular systems; land mobile radio propagation factors; mobile communication; electromagnetic propagation

\section{Introduction}

$\mathbf{T}$ The complexity of radio propagation in urban environments makes it increasingly difficult to fully understand and accurately predict propagation behavior in order to achieve an optimal network configuration [2, 3]. As better radio-propagation measurement systems become available, the limitations of the propagation-prediction tools that network operators use become more apparent. This also makes it clear that networks designed with such tools have a significant probability of being sub-optimal $[4,5]$. It is known to operators that in specific areas in operational radio networks, propagation phenomena can cause unexpectedly poor performance. This includes limited coverage, dropped calls, decreased data rates, and unexpected handovers. In order to obtain better insight and possibly solve these issues, more knowledge about the actual propagation effects is required. The use of more-advanced propagation-prediction methods, based on ray-launching or raytracing, can give more insight [6]. However, these models require accurate calibration, and do not always include all dominant propagation phenomena for the environment under test. Although the results of "drive tests" are sometimes used in an attempt to obtain more insight into the propagation phenomena, they merely give an observation of the effects. The quality and resolution of these results are limited, and only signal strengths are measured.
To date, only a few methods exist that can accurately identify the propagation effects in mobile scenarios. In [7], a measurement system was described based on a virtual uniform circular array that could be used to characterize the angular properties of the channel at the receiver in a static scenario with high resolution in azimuth, but with limited resolution in elevation. In [8], a method was presented based on a virtual rectangular array lattice to obtain improved elevation resolution. Due to the large measurement duration, this system could only be used for static measurements. In $[9,10]$, systems were presented based on spherical and semispherical switched arrays that are capable of measuring radio channels at the receiver while moving; however, the performance in both angular domains was poor. Measurements of the directional propagation effects at both the transmitter and receiver were reported in [11, 12], using the Elektrobit PropSound Channel Sounder [13]. Similar measurements were also reported in [14, 15], using the RUSK ATM channel sounder [16]. Although these double-directional measurements provided much information about the double-directional propagation behavior, the system complexity either limited the ability to perform measurements while moving through the environment, or limited the angular-resolution performance.

The measurement approach presented in [1] was capable making very accurate angle-of-arrival (AOA) and delay measure- 
ments, enabling the accurate characterization of the dominant propagation effects with high resolution and under mobile conditions. In the work described here, it is shown that this approach can be very helpful in obtaining more insight into propagation phenomena in real-world scenarios. The use of video data allows identifying the important scatterers, and relating the propagation effects directly to the environment. This information is very useful for system operators in order to improve network performance by adequate propagation prediction.

In the framework of a collaboration between the Eindhoven University of Technology (TU/e) in the Netherlands, the Netherlands Organization for Applied Scientific Research on Information and Communication Technology (TNO ICT), and Koninklijke PTT Nederland (KPN), the measurement system was used as a diagnostic tool in a dense urban environment. In this specific environment, poor performance was previously observed from the results obtained from "drive tests." The poor performance was caused by unexpected reduction of the power of the desired base-station (BS) signal and interference from a neighboring base station. The propagation phenomena that cause these effects are not predicted by the type of propagation models that are currently used by most mobile-system operators, including KPN. This means that it is impossible to improve the network performance in these areas based on the current propagation models. In order to identify the propagation phenomena that caused the poor performance, the high-resolution measurement system was configured such that it generated propagation behavior similar to the actual network, and measurements were performed in the area.

This paper describes the diagnostic survey and the results of the analysis. It is shown that the measurement approach can be used to generate a real network scenario. It is shown that the approach is capable of accurately identifying the dominant propagation effects with high resolution while moving through a realworld urban scenario.
Firstly, Section 2 describes the scenario, the environment, and the problems in terms of poor performance and interference. Secondly, Section 3 discusses the initial propagation-prediction results used for the network design. In Section 4, the measurement setup and procedure, as well as the results of the measurements, are presented. Here, the effects of shadowing and, moreover, reflections by irregular surfaces, are shown to be significant. Furthermore, the limitations of the currently used propagation-prediction model, and the importance of improved propagation modeling, are illustrated. Finally, conclusions are drawn in Section 5.

\section{Scenario Description}

The area that was selected for measurements is shown in Figure 1. It was located close to the Amsterdam Arena Stadium, near the city of Amsterdam, the Netherlands. The area was characterized by a main wide street $(20-25 \mathrm{~m})$, and a number of railway crossovers. Several three-to-seven-story-high buildings could be found in the area, consisting of concrete and steel, and with irregular faces caused by balconies and windows. Trees were found along the main street, and also scattered across the entire area. The traffic density during the measurements was low (five to 10 cars per minute). A single-frequency UMTS (Universal Mobile Telecommunications System) network was operational in the area, with two base stations located at positions marked by Tx 1 and Tx 2, as shown in Figure 1. The frequencies for the downlink and uplink channels were $2132.2 \mathrm{MHz}$ and $1942.2 \mathrm{MHz}$ respectively, for both base stations. At each base station, directional antennas were used as sector antennas, which exhibited a horizontal halfpower beamwidth of $88^{\circ}$ and a gain of $16.7 \mathrm{dBi}$. The antennas were driven by a $43 \mathrm{dBm}$ signal. A mobile UMTS user (receiver), which moved in the area close to the trajectory marked with the red and green dotted lines in Figure 1, was to be served by one of these base stations.

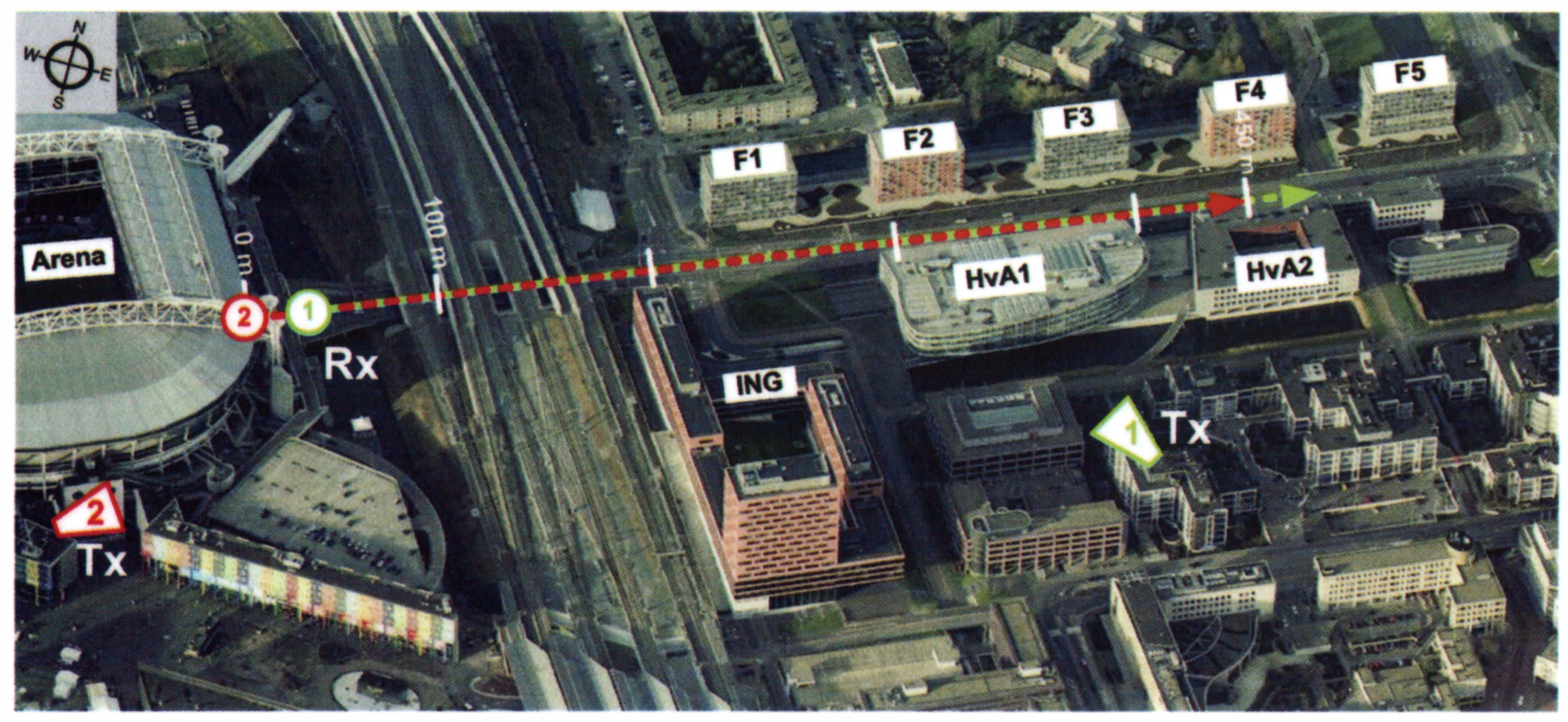

Figure 1. The layout of the measurement site. The green and red dotted lines represent the measurement trajectories, with the transmitter, Tx, active at Base Station 1 and Base Station 2 (underlying image copyright Microsoft Virtual Earth, http://www.microsoft.com/virtualearth). 


\section{Stochastic Empirical Prediction Results}

The network was designed such that the area along the main wide street was served best by Base Station 1 . This was confirmed by the results in Figure $2 b$, which showed the best server area for Base Station 1 (orange) and Base Station 2 (light grey). The simulation results were obtained from a stochastic empirical propagation model. The empirical model was developed by KPN for fieldstrength predictions, and was a modification of the widely used Okumura-Hata model [17]. The model did not include reflections or diffractions, but was based only on path-loss calculations. In order to increase the accuracy of the Okumura-Hata model, KPN expanded the model by including more detailed information about the propagation environment. Therefore, the area was subdivided into a grid of square subdomains of dimensions $20 \mathrm{~m} \times 20 \mathrm{~m}$, each with its own environmental classification, shown in Figure 2a. The different classifications ranged from open area (white), water (blue), and vegetation (green), to urban (brown), and each of the classifications was related to a certain amount of propagation loss. Because of confidentiality reasons, KPN could not provide exact details of the classifications. Signal powers were determined from the total path loss, according to the area classifications.
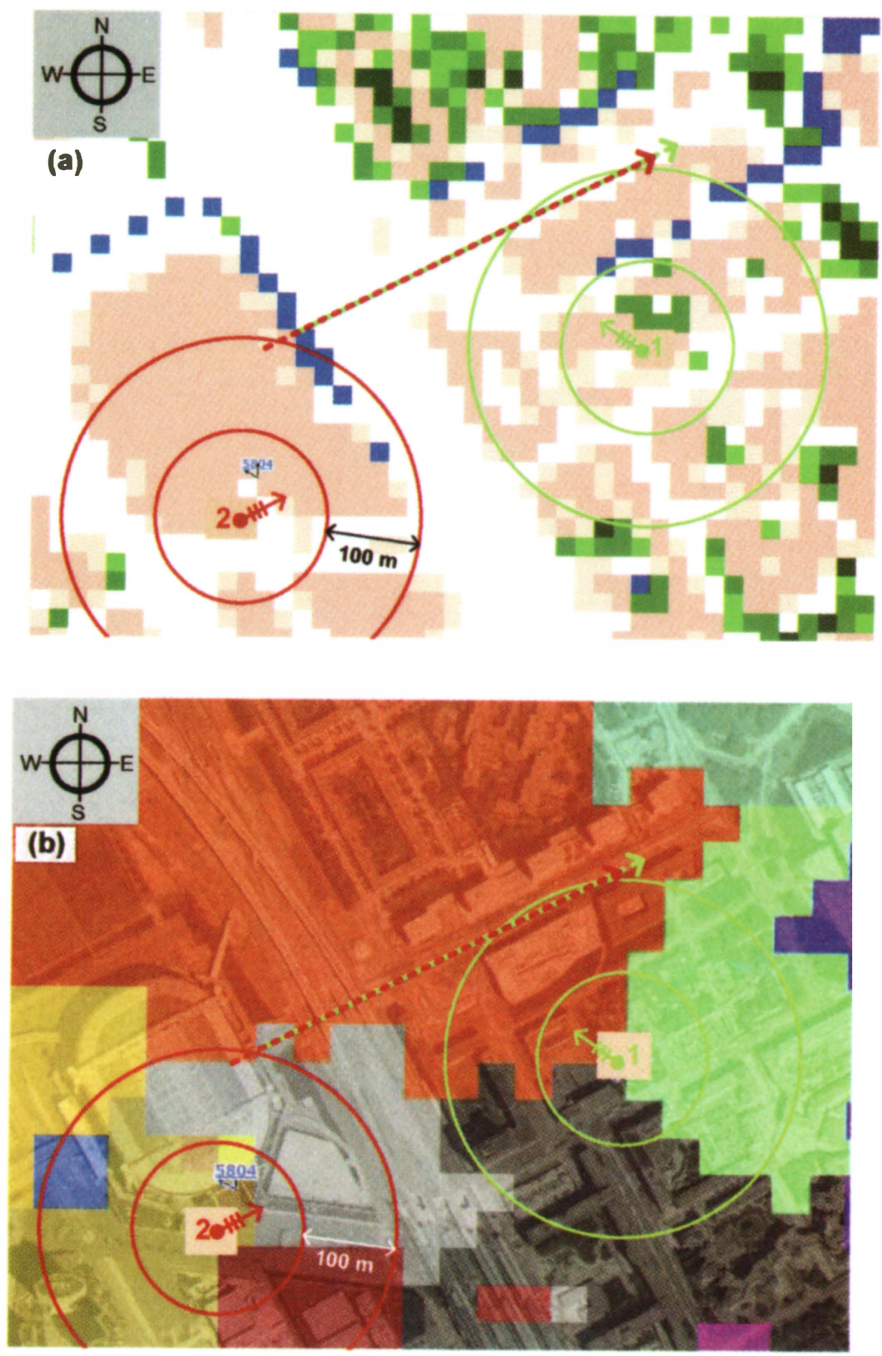

Figure 2. The layout of measurement site with (a) the grid of environmental classifications with open area (white), water (blue), vegetation (green), and urban (brown); and (b) the bestserved areas for Base Station 1 (orange) and Base Station 2 (light grey), determined using the stochastic empirical propagation model discussed in Section 3.
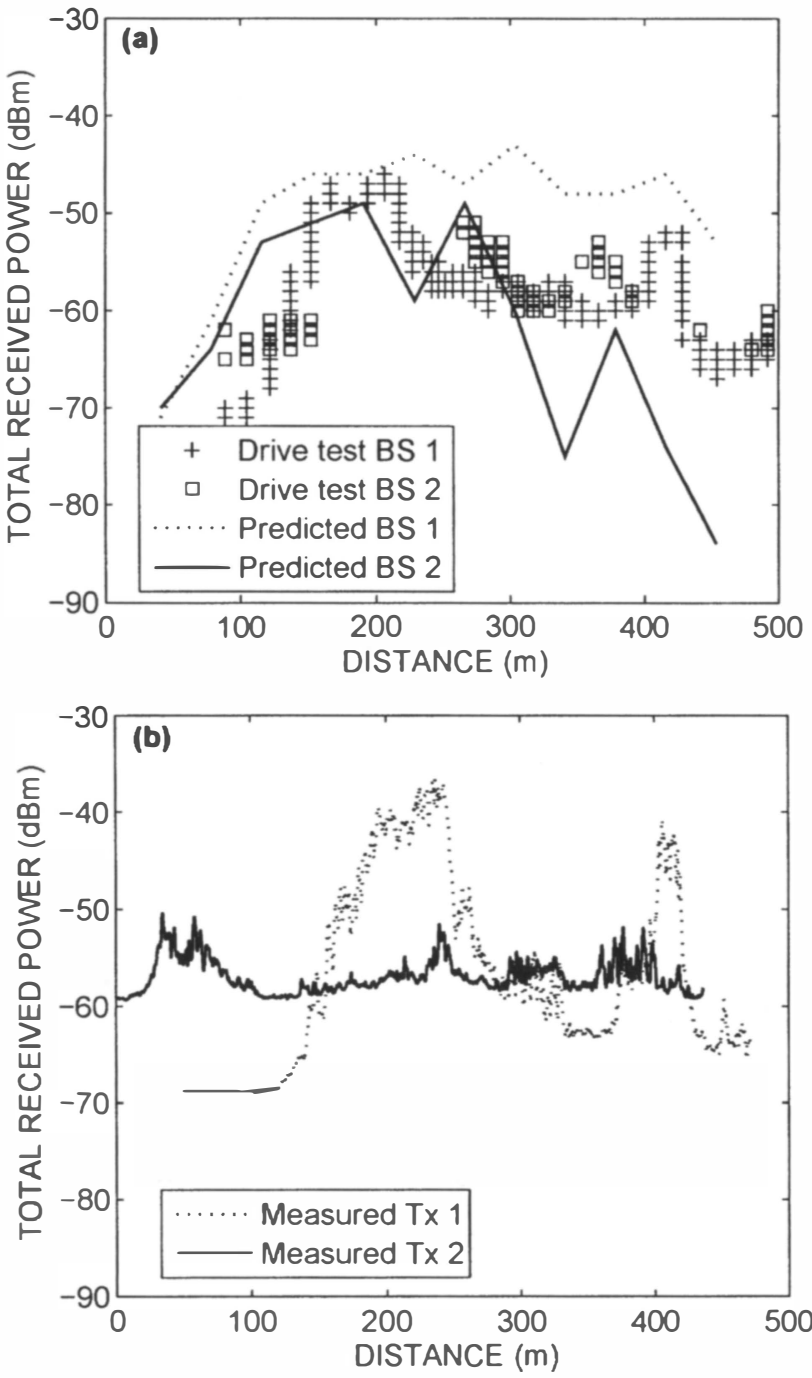

Figure 3. The measured power of both base stations along the trajectory obtained from (a) a previous KPN drive test and predictions using the stochastic empirical model discussed in Section 3; and (b) from the impulse responses obtained from the high-resolution measurement system.

Although this took local information into account in a broad sense, no information about reflections, backscattering, delay spread, or angular spread was considered. As a result, propagation predictions for dense urban areas often contained errors.

\section{Measurements}

Measurements were performed in the area in an earlier study by KPN. The results for the received power along the trajectory, as well as the predicted values, are shown in Figure 3a. For Base Station 1 , the received power was considerably below the predicted value, whereas for Base Station 2, the power at some positions was above the predicted value. As a result, the received power of the undesired base station was above that of the desired base station at several positions, which caused undesired handovers and a reduction in performance. To obtain more insight into the propagation phenomena that were significant in this area, and to find possible causes for the propagation-prediction errors, measurements were performed using the high-resolution measurement system 
described in [1]. This system operated in a bandwidth of $100 \mathrm{MHz}$ at a center frequency of $2250 \mathrm{MHz}$, which was close to the frequency of the actual UMTS network.

\subsection{Setup and Procedure}

Two independent measurements were performed in which the transmitter was placed at both base-station locations. The transmitting antenna consisted of an $8 \mathrm{dBi}$ waveguide horn antenna, with an azimuthal half-power beamwidth of $55^{\circ}$. A tripod was used to elevate the antenna such that it was in almost the same position and had the same orientation as the original base-station antenna: this is shown in Figure 4 for Base Station 2, as an example. Although there was a difference in the beamwidths between the horn antenna and the base-station antennas mentioned in Section 2, this was not considered very important in the diagnostic analysis presented here.

- In the first experiment, the transmitting antenna was positioned outside, at a height of $29 \mathrm{~m}$ above ground level, close to Base Station 1, marked in green in Figure 1 . The direction of the main beam was pointed towards $-60^{\circ}$ in azimuth, where $0^{\circ}$ corresponded to the north, and the positive angles were clockwise. No down-tilt in elevation was applied.

- In the second experiment, the transmitting antenna was positioned outside, at a height of $27 \mathrm{~m}$ above ground level, close to Base Station 2, marked in red in Figure 1. The direction of the main beam was pointed towards $70^{\circ}$ in azimuth, and no down-tilt was applied.

The receiving antenna consisted of a three-dimensional array of 31 monopole elements [1], and was mounted on top of a vehicle at a height of $3.5 \mathrm{~m}$. The backside of the vehicle corresponded to $0^{\circ}$ and the positive angles were anticlockwise. The array was moved at a nearly constant speed of about $27 \mathrm{~km} / \mathrm{h}$ over a trajectory of approximately $450 \mathrm{~m}$, indicated with green and red dotted lines in Figure 1 for the first and second experiments, respectively. A total of 9900 array snapshot sets of 10 snapshots were used for the angle-of-arrival estimation [18], which meant that a channel estimate was available every $4.5 \mathrm{~cm}$, corresponding to 0.34 wavelengths.

\subsection{Results}

In Figure $3 \mathrm{~b}$, the results of the total received power for both experiments along the trajectory are presented. The large-scale fluctuations of the power received from Tx 1 were similar to the KPN drive-test results in Figure 3a, obtained two months earlier in the same scenario. Furthermore, a more-constant received power level from Tx 2 was observed, which exceeded the level of Tx 1 along several parts of the trajectory. The difference in absolute power levels between the KPN drive test and the high-resolution measurements in Figures 3a and 3b was mainly due to insufficient information about the measurement equipment (e.g., cable attenuation, antenna patterns) used in the KPN drive test.

The results in Figure 5 show the estimated multipath components (MPCs) in the delay and angular domains along the trajectory obtained from the signals received by $\mathrm{Tx} 1$. Up to snapshot set $k \simeq 2000$, the received signal was very weak. Visual inspection of the environment showed that this was mainly caused by the obstruction of building ING. Apart from small reflections by building Arena and the railway infrastructure, through-building propagation was dominant in this area. Between $2000<k<5000$, the receiver moved into and out of the line-of-sight region, and the received power as well as the delay spread and angular spread increased. Particularly in the azimuth domain, a number of distinct components were visible, which seemed to change rapidly in the azimuth direction. From the omnidirectional video data, it was found that these distinct components were caused by reflections from lampposts, traffic signs, and plane metallic objects.

A number of other more-diffuse and less rapidly changing components were also visible. By using the omnidirectional camera data, these components could be related to reflections from irregular (building) surfaces and objects, and through-building propagation.

The results in Figures 7-10 each contained the estimated multipath components, superimposed on a video frame, from the transmitter at Base Station 1 (Figures 7a, 8a, 9a, 10a) and from the transmitter at Base Station 2 (Figures $7 \mathrm{~b}, 8 \mathrm{~b}, 9 \mathrm{~b}, 10 \mathrm{~b}$ ), at a comparable receiver position. Figure $7 \mathrm{a}$ shows the estimation results of snapshot $k=3900$. Here, the line-of-sight component was clearly visible, as well as other components caused by reflections from buildings, traffic signs, and other objects.

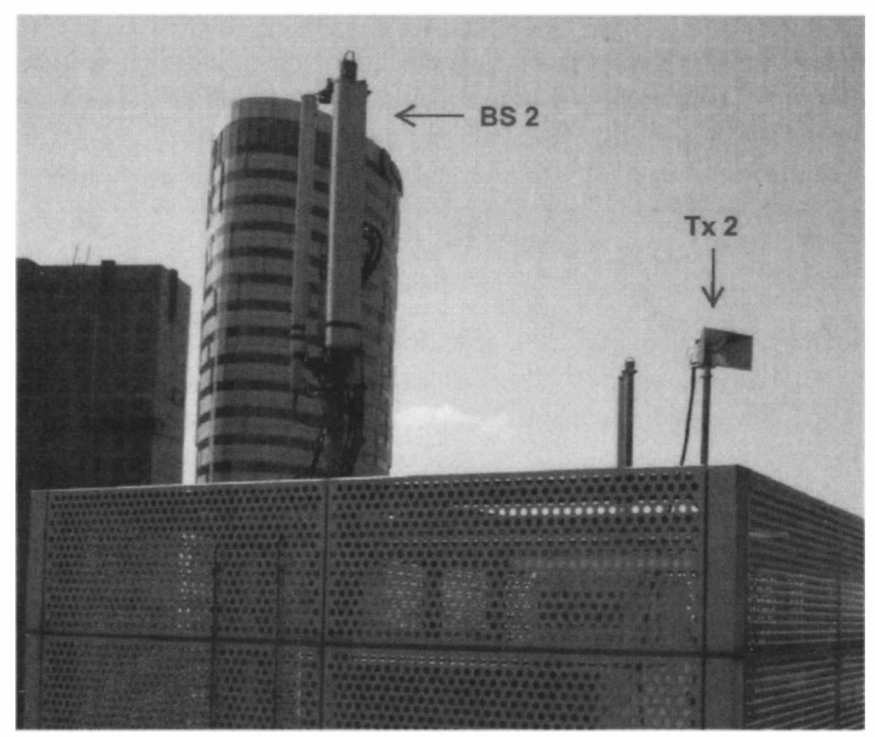

Figure 4. The transmitting antenna, $T \times 2$, positioned outside, close to Base Station 2, and pointed in the same direction. 

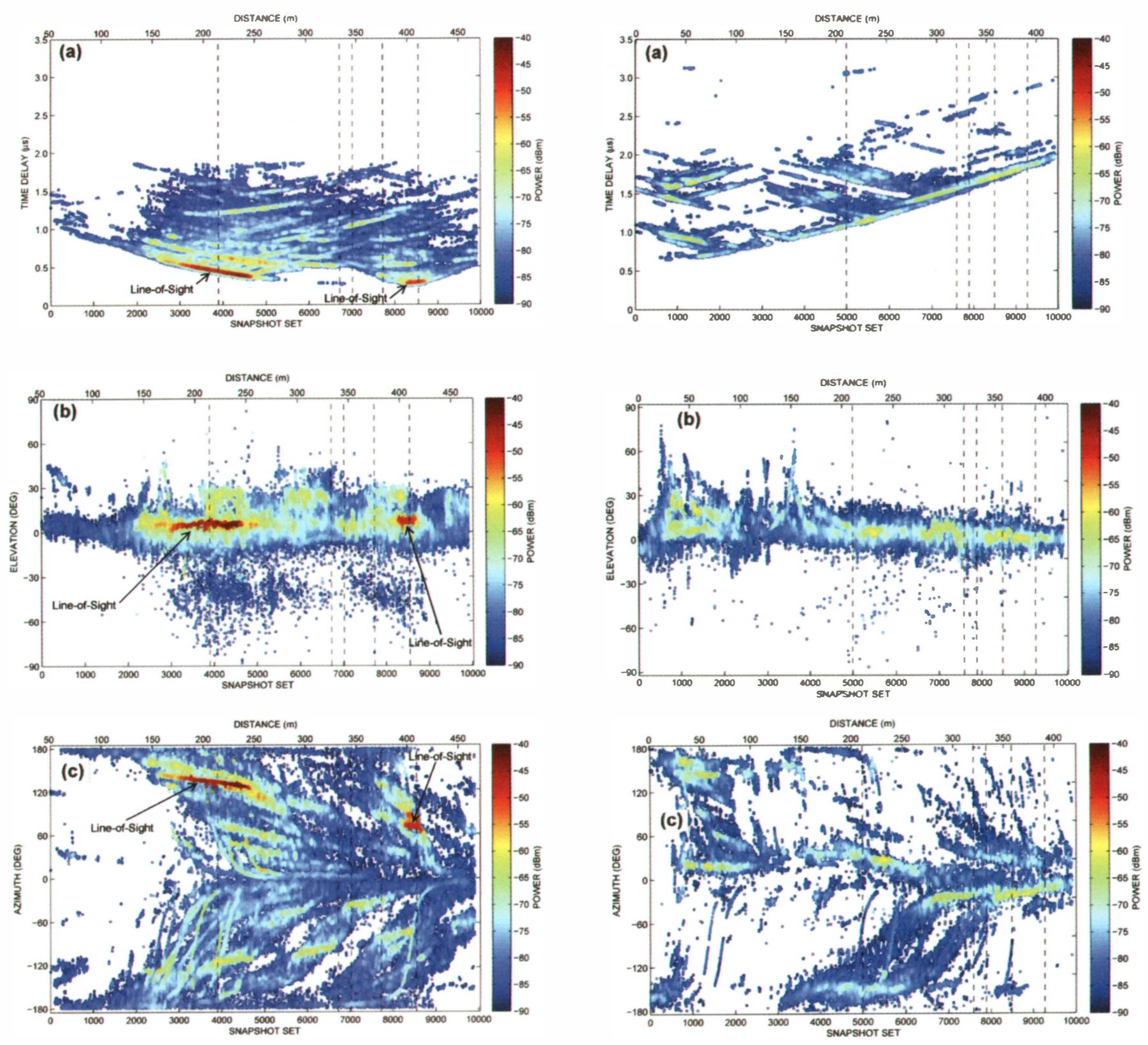

Figure 5. The estimated multipath components along the measurement trajectory from the signals received from $T \times 1$ in the (a) delay, (b) elevation, and (c) azimuthal domains.

During the remaining part of the trajectory, the receiver remained mainly in the non-line-of-sight region. Reflections mainly from the upper parts of buildings F1 to F4, shown in Figure 1 , were also visible in the elevation domain as consecutive collections of multipath components at larger elevation angles. These collections of multipath components were visible in the azimuth domain as bands that changed from $\phi \simeq-180^{\circ}$ to $0^{\circ}$. These bands of multipath components consisted of a stronger specular component as well as a more diffuse part. The scattering in the diffuse part was caused by the irregular structure of the buildings, consisting of irregularly distributed windows and steel balconies. The results in Figures 8a and 9a show the estimates at $k=6720$ and $k=7020$, respectively. In the short interval between $8250<k<8750$, a line-of-sight between HvAl and HvA 2 existed. The moment just before the line-of-sight region is also shown in

Figure 6. The estimated multipath components along the measurement trajectory from the signals received from Tx 2 in the (a) delay, (b) elevation, and (c) azimuthal domains.

Figure $10 \mathrm{a}$, where a strong reflection via $\mathrm{HvA} 2$ and a small amount of through-building propagation of HvAl is observed. The line-ofsight region is shown in Figure 1 la.

The results in Figure 6 show the estimated multipath components in the delay and angular domain along the trajectory obtained from the signals received by $\mathrm{Tx} 2$. Up to $k=3500$, most of the received power was received via reflections by the railway infrastructure and crossovers, as well as via propagation around and through building Arena. The vertical spikes in the elevation domain resulted from propagation through the vertical open parts of the railway crossovers. From $3500<k<6000$, two more dominant contributions were visible. The strongest contribution, varying from $\phi \simeq 30^{\circ}$ to $0^{\circ}$, was caused by propagation over the railway crossovers. 

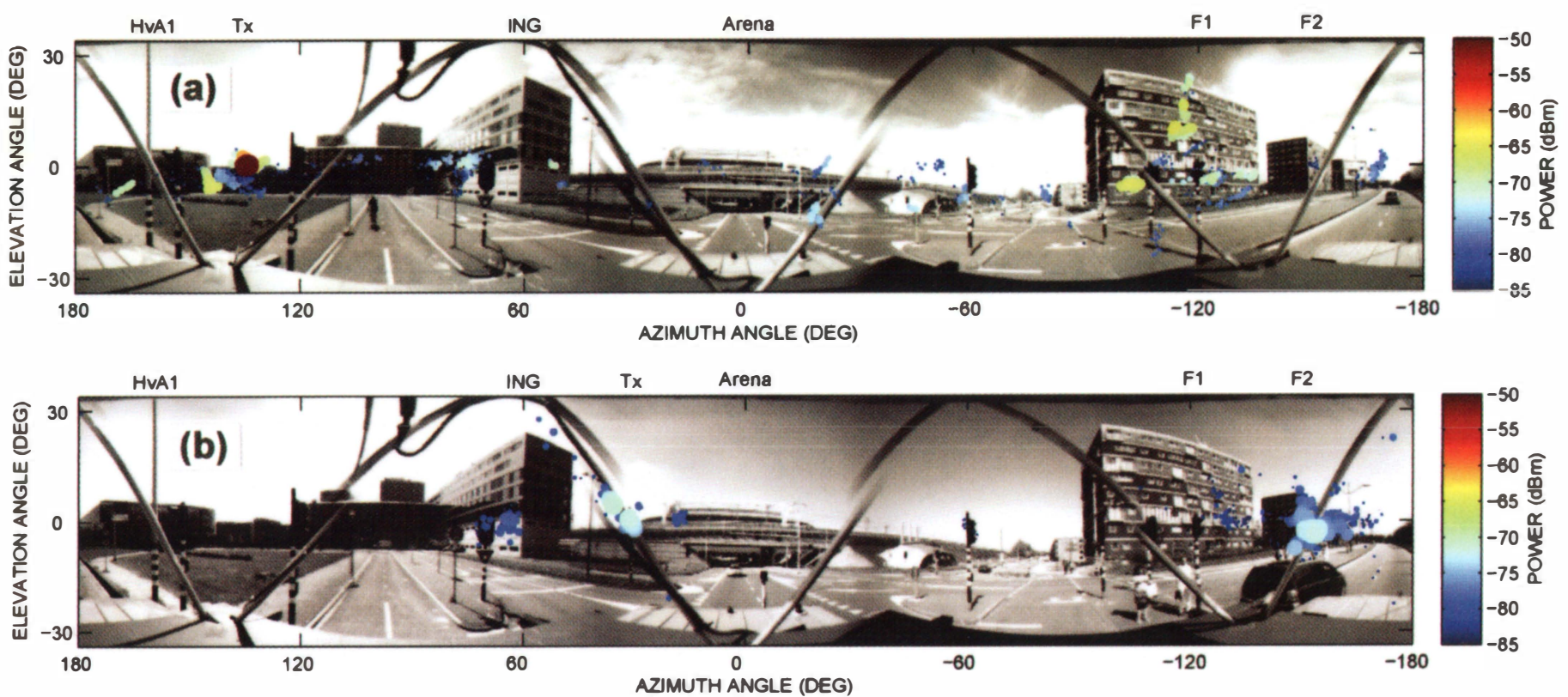

Figure 7. The multipath component angles-of-arrival superimposed on omnidirectional video data for (a) the Tx at Base Station 1 and $k=3900$, and (b) the $\mathrm{Tx}$ at Base Station 2 and $k=4995$. In this figure and all subsequent figures, the received power is represented by the color as well as the size of the markers, where the largest marker corresponds to the highest received power.
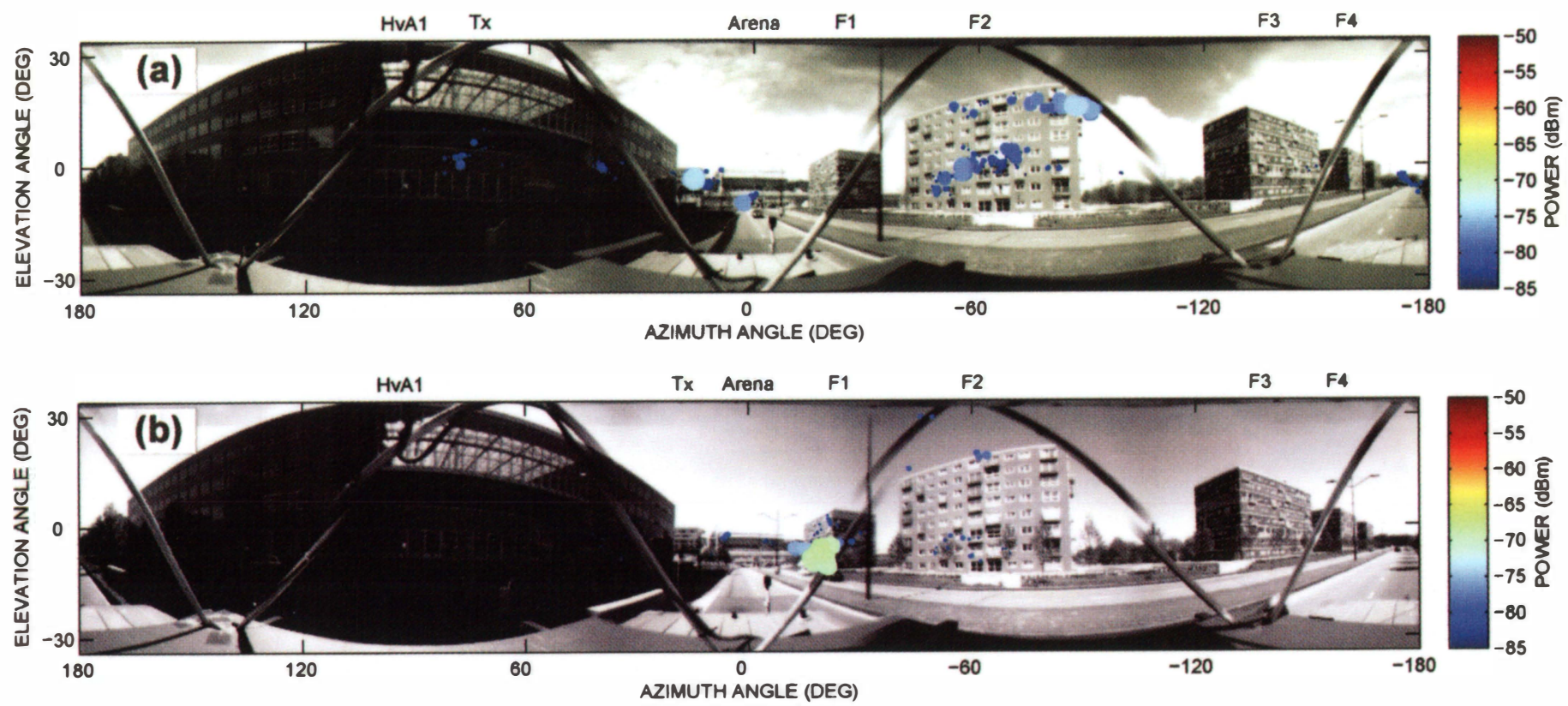

Figure 8. The multipath component angles-of-arrival superimposed on omnidirectional video data for (a) the Tx at Base Station 1 and $k=6720$, and (b) the Tx at Base Station 2 and $k=7590$. 

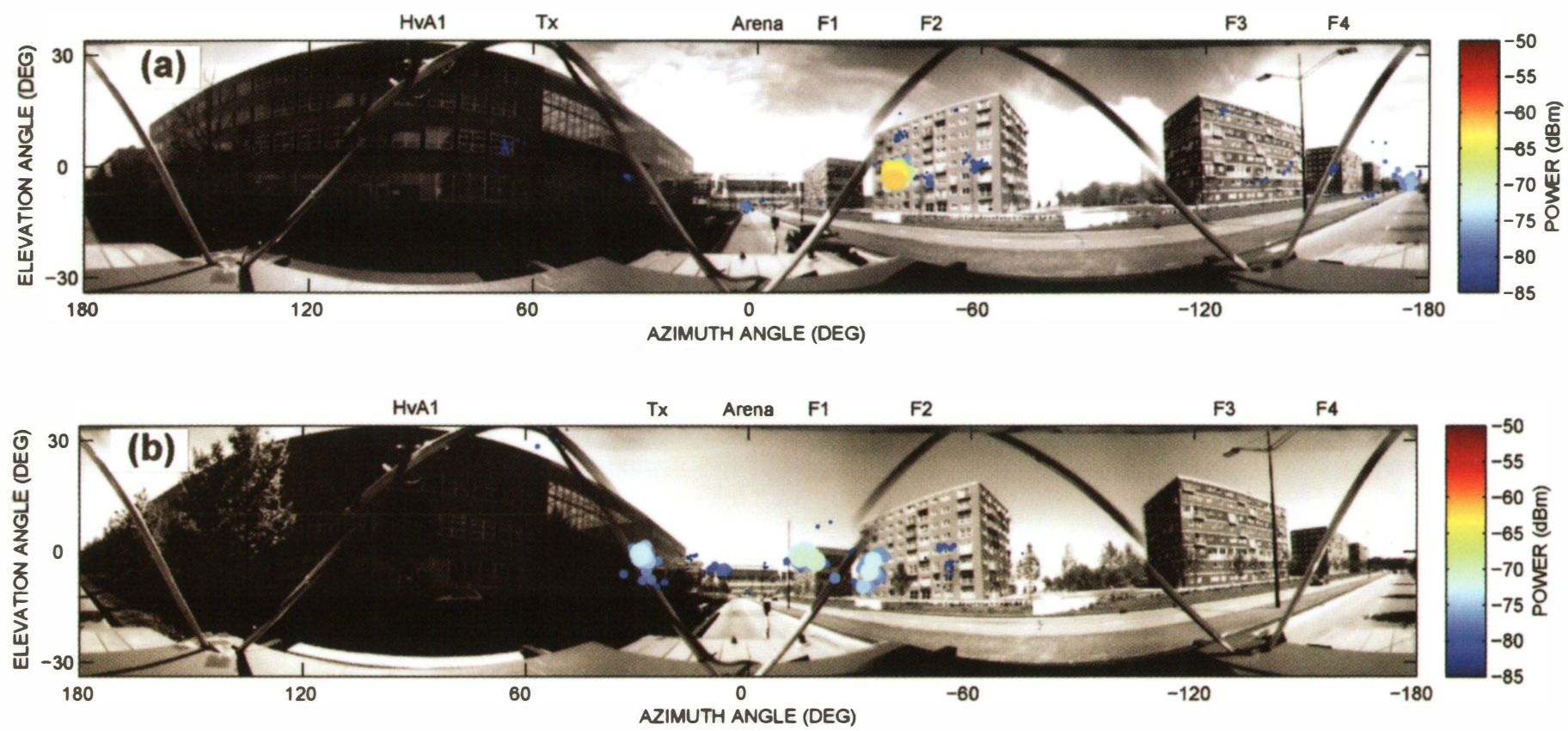

Figure 9. The multipath component angles-of-arrival superimposed on omnidirectional video data for (a) the ' $\mathrm{l} x$ at Base Station 1 and $k=7020$, and (b) the Tx at Base Station 2 and $k=7890$.
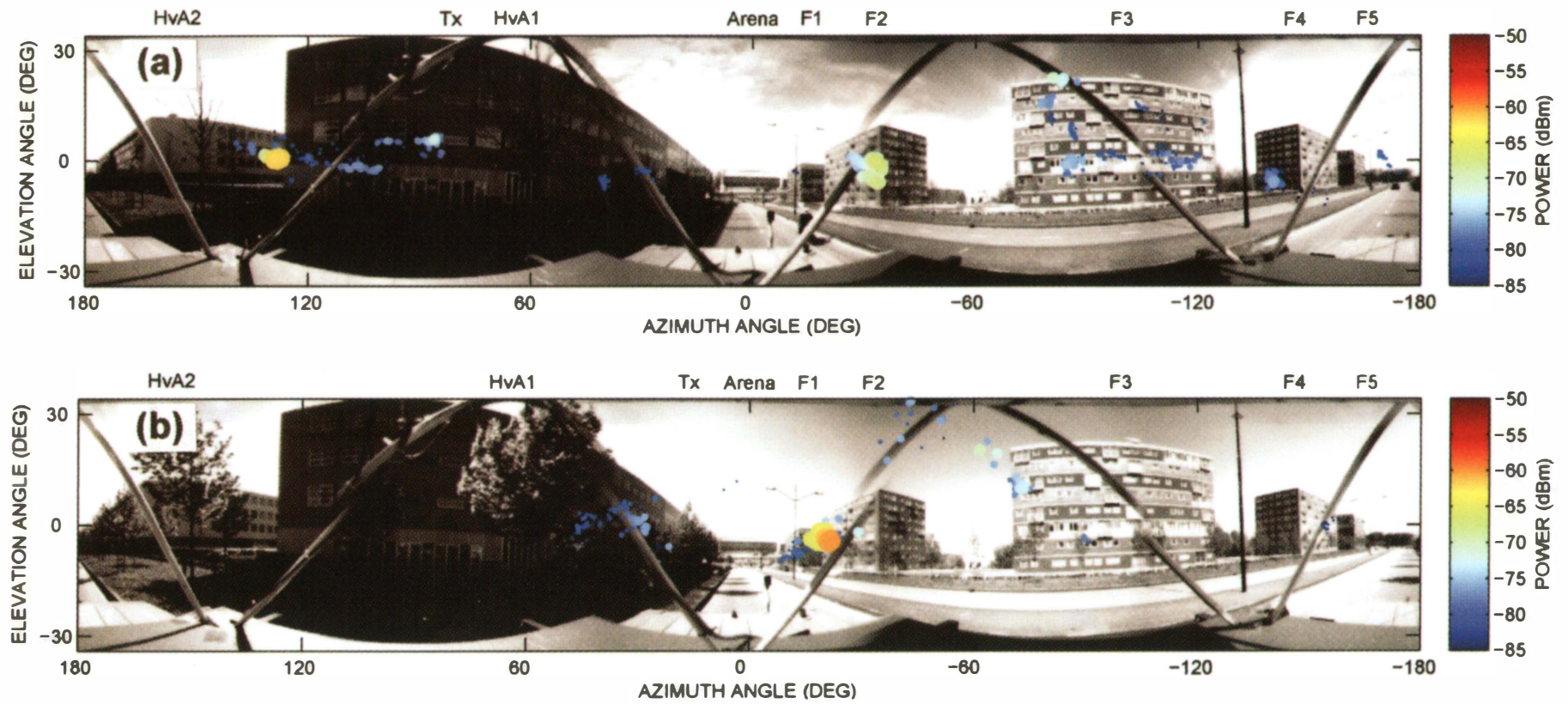

Figure 10. The multipath component angles-of-arrival superimposed on omnidirectional video data for (a) the Tx at Base Station 1 and $k=7725$, and (b) the Tx at Base Station 2 and $k=8490$. 

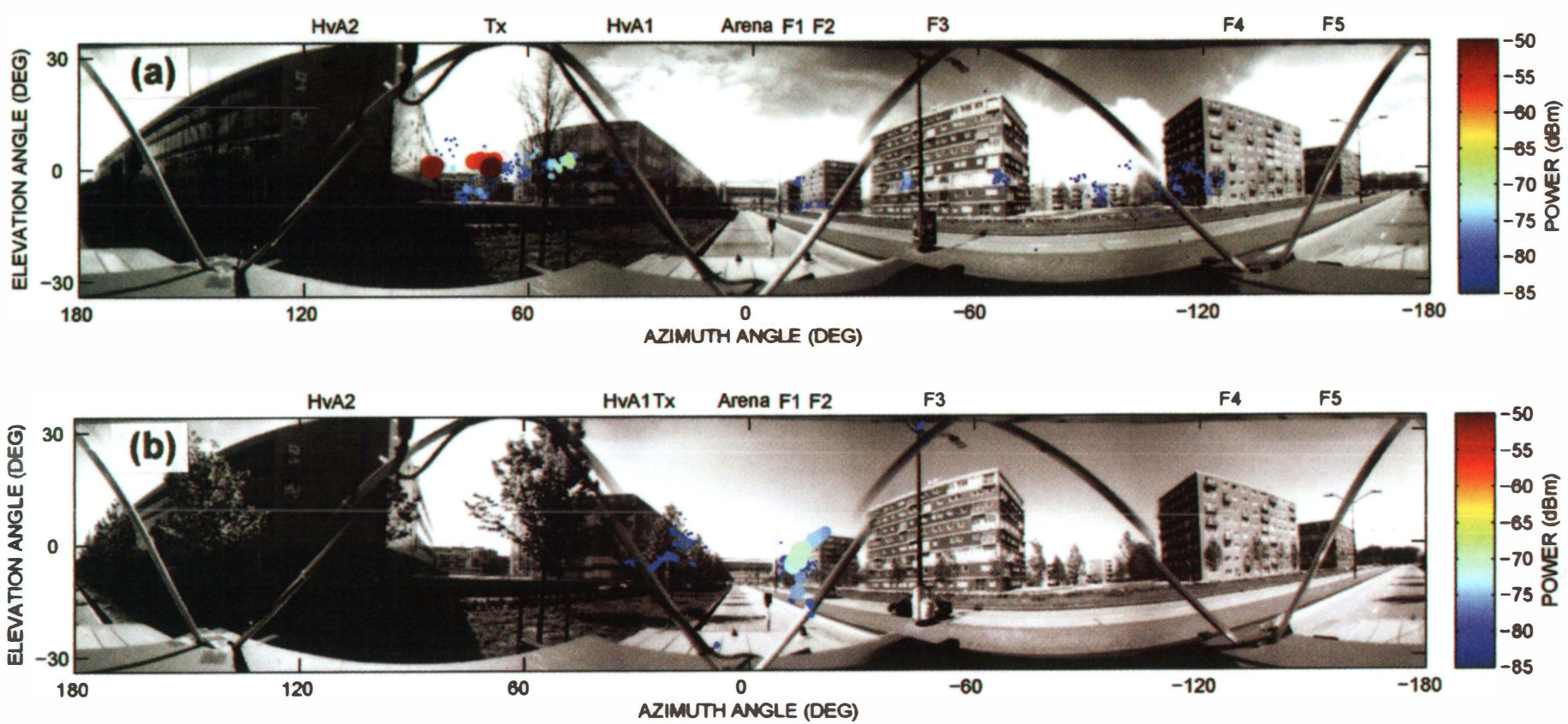

Figure 11. The multipath component angles-of-arrival superimposed on omnidirectional video data for (a) the Tx at Base Station 1 and $k=8551$, and (b) the $T \times$ at Base Station 2 and $k=9271$.

The other lower and more-diffuse contribution was caused by the front and side faces of building F2, perpendicular to the trajectory. This is visualized in Figure $7 \mathrm{~b}$, where the two strong collections of multipath components were clearly visible. A small amount of through-building propagation was observed at building ING, but this was much weaker than the reflections from building F2. The collections of multipath components from building F2 are also visible in Figure $6 \mathrm{c}$ as a band that changes from $\phi \simeq-180^{\circ}$ to $0^{\circ}$. Although no specular path existed from the transmitter to the receiver via the face of building F2, scattering caused by the irregularities still caused significant power to reach the receiver. In the second part of the trajectory $(k>5000)$, similar significant contributions by reflections from building $F 1$ and $F 2$ were visible, as well as second-order reflections, most likely from the buildings HvAl and HvA2 and the trees in front of them. This is also visualized in Figures $8 \mathrm{~b}-11 \mathrm{~b}$. Figure $8 \mathrm{~b}$ shows that at $k=7590$, the scattering of remote building F1 was much larger than the scattering of the nearby building F2. It could be seen from Figure 6 that the scattering of building $F 1$ reached its maximum around $\boldsymbol{k}=7000$, while that of building F2 had a maximum around $k=8500$ (see also Figure 10b). This clearly demonstrated that the scattering at these buildings was not completely diffuse.

From the results discussed above, it became clear that the received power - overestimated by the propagation prediction model - and the large-scale signal fluctuations of the received signal from Tx 1 were mainly caused by the strong shadowing effects by buildings HvAl and HvA2. Although in the shadowed areas, part of the energy was reflected back via the upper half of buildings F1-F4, the amount of total received power was below that of Tx 2, for a large part. This can be seen more clearly in Figure 3b. The underestimated or relatively high received power from $T \times 2$ was mainly caused by through-building propagation, reflections from rough building surfaces (F1-F4), and higher-order reflections. These effects caused the waves to propagate rather easily into and through this street.

The results also showed that the prediction errors in the stochastic empirical propagation-prediction model were mainly caused by the limited amount of information about the environment that was taken into account, and important propagation mechanisms, such as reflections, that were not directly included in the model. Furthermore, it was shown that in the case of irregular surfaces, the effects of an entire surface can be important, instead of those from a single specular point.

Other type of models, e.g., ray-based models [3, 19], will need to be considered in order to include propagation effects that cause energy to arrive via paths other than only the direct path. However, the use of ray-based models for diagnostic site analysis will not always be the right solution, since the dominant propagation phenomena may not all be correctly included in the model. Furthermore, incorrect calibration of the model may cause severe under-estimation or overestimation of the propagation phenomena. The results from diagnostic measurements, as presented here, may lead to extensions, improvements, and better calibration of raybased models. When a more in-depth analysis of a specific area is required, the use of these improved ray-based prediction tools can then be used to improve the network configuration.

\section{Conclusions}

In this paper, a high-resolution measurement system was used as a diagnostic tool in a dense urban environment in order to identify the causes of unexpected interference and signal degradation in an active cellular network. It was shown that the measurement system can be configured so as to operate in propagation conditions similar to those that influence the operation of live operating systems, in order to identify the causes of unexpected interference and desired signal degradation in the corresponding active cellular system. The high-resolution capabilities, and the combination of omnidirectional video images and measurement data, make it possible to directly identify propagation effects in a real network scenario while moving through it. 
The results underlined the limitations of current propagation models used by operators in existing and - even more importantly - future networks. It was shown that shadowing and reflections from irregular building structures are important phenomena that are currently not accurately modeled, and this can lead to network problems in more-complex environments. More accurate propagation modeling is needed in complex environments. The use of advanced propagation measurements can help provide the insight needed for the development of such models.

\section{Acknowledgment}

The authors would like to thank Jaap Swijghuizen Reigersberg and Rainier van Dommele for technical support. The authors also acknowledge the support of TNO ICT and KPN. In particular, the first author was financially supported within the research framework Dutch Research Delta, a research cooperation between KPN, TNO, and a number of Dutch universities.

\section{References}

1. M. R. J. A. E. Kwakkernaat, Y. L. C. de Jong, R. J. C. Bultitude, and M. H. A. J. Herben, "High-Resolution Angle-of-Arrival Measurements on Physically-Nonstationary Mobile Radio Channels," IEEE Transactions on Antennas and Propagation, AP-56, 8, August, 2008, pp. 2720-2729.

2. T. K. Sarkar, Zhong Ji, Kyungjung Kim, A. Medouri, and M. Salazar-Palma, "A Survey of Various Propagation Models for Mobile Communication," IEEE Antennas and Propagation Magazine, 45, 3, 2003, pp. 51-82.

3. H. L. Bertoni, S. A. Torrico, and G. Liang, "Predicting the Radio Channel Beyond Second-Generation Wireless Systems," IEEE Antennas and Propagation Magazine, 47, 4, 2005, pp. 28-40.

4. M. Coinchon, A.-P. Salovaara, and J.-F. Wagen, "The Impact of Radio Propagation Predictions on Urban UMTS Planning," International Zurich Seminar on Broadband Communications, February 19-21, 2002, pp. 1-6.

5. O. C. Mantel, J. C. Oostveen, and M. P. Popova, “Applicability of Deterministic Propagation Models for Mobile Operators," 2nd European Conference on Antennas and Propagation (EuCAP 2007), 2007, pp. 1-6.

6. M. Dottling, A. Jahn, D. Didascalou, and W. Wiesbeck, "Twoand Three-Dimensional Ray Tracing Applied to the Land Mobile Satellite (LMS) Propagation Channel," IEEE Antennas and Propagation Magazine, 43, 6, December, 2001, pp. 27-37.

7. Y. L. C. de Jong and M. H. A. J. Herben, "High-Resolution Angle-of-Arrival Measurement of the Mobile Radio Channel," IEEE Transactions on Antennas and Propagation, AP-47, 11, November, 1999, pp. 1677-1687.

8. J. Fuhl, J.-P. Rossi, and E. Bonek, "High-Resolution 3-D Direction-of-Arrival Determination for Urban Mobile Radio," IEEE Transactions on Antennas and Propagation, AP-45, 4, 1997, pp. 672-682.

9. V.-M. Kolmonen, J. Kivinen, L. Vuokko, and P. Vainikainen, "5.3-GHz MIMO Radio Channel Sounder," IEEE Transactions on
Instrumentation and Measurement, 55, 4, August, 2006, pp. $1263-$ 1269.

10. K. Kalliola, H. Laitinen, L. I. Vaskelainen, and P. Vainikainen, "Real-Time 3-D Spatial-Temporal Dual-Polarized Measurement of Wideband Radio Channel At Mobile Station," IEEE Transactions on Instrumentation and Measurement, 49, 2, April, 2000, pp. 439448.

11. M. Alatossava, L. Hentila, V. M. Holappa, and J. Meinila, "Comparison of Outdoor to Indoor and Indoor to Outdoor MIMO Propagation Characteristics at $5.25 \mathrm{GHz}$," Proceedings of the IEEE 65th Vehicular Technology Conference (VTC 2007 Spring), 2007, pp. 445-449.

12. Xinying Gao, Jianhua Zhang, Guangyi Liu, Ding Xu, Ping Zhang, Yang Lu, and Weihui Dong, "Large-Scale Characteristics of $5.25 \mathrm{GHz}$ Based on Wideband MIMO Channel Measurements," IEEE Antennas and Wireless Propagation Letters, 6, 2007, pp. 263-266.

13. E. Zollinger, "A Novel Architecture for a Flexible Integrated Wideband Vector Channel Sounder for MIMO System Investigation," General Assembly of the International Union of Radio Science, Maastricht, Netherlands, 2002.

14. M. Steinbauer, A. F. Molisch, and E. Bonek, "The DoubleDirectional Radio Channel," IEEE Antennas and Propagation Magazine, 43, 4, August, 2001, pp. 51-63.

15. T. Zwick, D. Hampicke, A. Richter, G. Sommerkorn, R. Thoma, and W. Wiesbeck, "A Novel Antenna Concept for DoubleDirectional Channel Measurements," IEEE Transactions on Vehicular Technology, 53, 2, 2004, pp. 527-537.

16. R. S. Thoma, D. Hampicke, A. Richter, G. Sommerkorn, A. Schneider, U. Trautwein, and W. Wirnitzer, "Identification of Time-Variant Directional Mobile Radio Channels," IEEE Transactions on Instrumentation and Measurement, 49, 2, 2000, pp. 357-364.

17. M. Hata, "Empirical Formula for Propagation Loss in Land Mobile Radio Services," IEEE Transactions on Vehicular Technology, 29, 3, 1980, pp. 317-325.

18. M. R. J. A. E. Kwakkernaat, Y. L. C. Jong, J. C. Bultitude, and M. H. A. J. Herben, "Improved Structured Least Squares for the Application of Unitary Esprit to Cross Arrays," IEEE Signal Processing Letters, 13, 6, 2006, pp. 349-352.

19. L. W. Barclay, Propagation of Radiowaves, Second Edition, London, IEE, 2003.

\section{Introducing the Feature Article Authors}

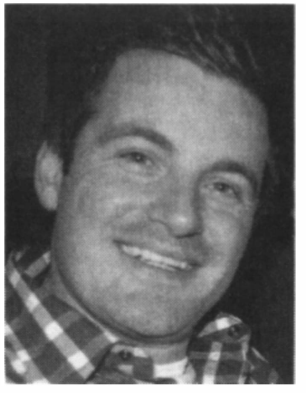

Maurice R. J. A. E. Kwakkernaat was born in Venray, The Netherlands, in 1978. He received the PhD and MSc in Electrical 
Engineering from Eindhoven University of Technology (TU/e), Eindhoven, The Netherlands, in 2004 and 2008, respectively. In January 2009, he joined TMC Electronics, Eindhoven, The Netherlands. His research interests include wireless and mobile communication systems, radar technology, algorithm design, radioresource management, and wireless-propagation analysis. He is a member of the IEEE, the Royal Institute of Engineers in The Netherlands (KIvI), and the Dutch Electronics and Radio Society (NERG). In 2007, he received a Best Paper Award at PIMRC 2007. In 2008, he received the 2008 Netelcom Award from the professional organization of suppliers of telecommunication equipment in the Netherlands (Netelcom).

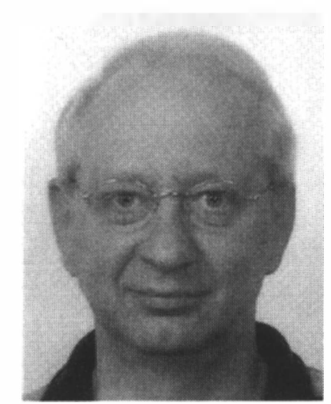

Matti H. A. J. Herben was born in Klundert, The Netherlands, in 1953. He received the MSc degree (cum laude) in Electrical Engineering and the PhD degree in Technical Sciences from Eindhoven University of Technology (TU/e), Eindhoven, The Netherlands, in 1978 and 1984, respectively. He has been with the Radiocommunications Group at TU/e since 1978, where he currently is as an Associate Professor. He was Associate Editor of Radio Science from 1993 to 1996, and has been Associate Editor of the IEEE Transactions on Antennas and Propagation since 2007. His research interests and publications are in the areas of antennas, radio wave propagation, channel modeling for wireless communications, and atmospheric remote sensing. Dr. Herben is a member of the IEEE, the Royal Institute of Engineers (KIvI), the Dutch Electronics and Radio Society (NERG), the Dutch URSI Committee, Treasurer of the IEEE Benelux joint Chapter on Communications and Vehicular Technology, and a member of the Management Committee of the COST Action 2100 - "Pervasive Mobile Ambient Wireless Communications." 